\title{
Note from Rwanda
}

\author{
Sydney Brandon
}

Since the genocide of 1994 I have been a regular visitor to Rwanda and have been deeply impressed by the resilience of the people. Their remarkable achievements in restoring the basic infrastructure which was destroyed in the fighting of 1994 have happened despite grinding poverty and much personal suffering.

The recent massive return of Hutu refugees from Zaire (now The Democratic Republic of The Congo) and elsewhere has been accompanied by sporadic guerrilla activity by returning former soldiers of the old regime and Interhamwe militia. They have mingled with the returnees and emerge at night to collect uniforms and arms from hidden caches, and after their bloody work merge back into the community. Cross-border incursions by the former army make the Western prefectures dangerous, but even here there are signs of hope.

A raiding party attacked a senior school in Kibuye and demanded that the students segregate themselves, with Hutu at one end of the Hall and Tutsi at the other. The boys replied "we are all Rwandans here" and in reply grenades were thrown through the open windows killing 10 boys and wounding 20 others.

On the whole those who have returned have been accepted back into their old communities. Some who actively participated in the slaughter have been arrested but there is little evidence of indiscriminate retribution. There are, however, many realistic fears among the Tutsi that once again this minority group will be subjected to systematic slaughter. Only the Rwanda Patriotic Army stands between the two groups.

The two major ethnic groups, Hutu and Tutsi, are no longer distinct after years of intermarriage and there are few real cultural differences between them. The longing for peace and reconciliation is strong but the Hutu from the camps in Zaire have for three years been subjected to intense propaganda calling for a return to Rwanda to complete the elimination of the Tutsi.

The National University has reopened and the Government has decided to hasten progress towards meeting its aim that both French and English should be official languages by devoting the next six months to language teaching only. All students and the largely Francophone faculty will have to achieve fluency in both languages by the end of September. From the beginning of next year teaching and examining may be in either language. This is a formidable undertaking given the paucity of resources and lack of enthusiasm in at least some of the faculty. One hopes that the UK will offer some help.

One of the tasks I have personally been undertaking is in offering support and teaching on psychological trauma to voluntary agencies, including the Catholic Church. One of the agencies is for widows of the genocide, many of whom are the only adult survivors of their family. Most are caring for many children - their own. those of relatives or orphans with no living relatives. There is no social security and all are dependent upon their own efforts.

On my last visit, over the course of three weeks, I met in small groups about 100 widows who had suffered frightening trauma and multiple losses and almost all still had active symptoms of post-traumatic stress disorder. Disturbed sleep was nearly universal and most still had frightening dreams. Many were afraid of soldiers and some felt uncomfortable in the presence of any men. All had some degree of hyper-vigilance with startle responses and anxiety symptoms. One reported total absence of fear since the events but I did not get a chance to discuss this in more detail with her. All described total recall of the terrifying incidents. A few said that they could no longer see the faces of their assailants clearly but knew who they were. Many had never told anyone the whole story and this was particularly true where rape was involved.

Many had residual avoidance of things or places related to the trauma, but none was severely phobic. This was presumably a consequence of the forced confrontation of their fears which was necessary for survival. The widespread complaints and the distress associated with them nearly three years after the events is interesting because there is no question of compensation or benefit deriving from the continued symptoms which in many cases were additional burdens in the struggle for survival.

The women were a mixed group containing some elementary school teachers but others who were barely literate, and almost all hooted with laughter when I advised them not to drink cola late at night. None of them could afford to. 
When I gave a standard account of grief and bereavement all recognised such behaviour in themselves. Although they agreed that in Rwandan culture it was expected that sorrow would be expressed only within the family and that tears should not be shed in public, many cried openly as they described their losses. The anger and irritability they found incomprehensible and they were relieved to hear this described as a normal phenomenon. They commented that their irritability often and usually unjustly fell upon their children. Later, when children's needs were under discussion, one woman asked "how is it possible to give children love when we are so busy just trying to survive?" Others nodded agreement. Many are homeless living in temporary shelters or sleeping on the floors of friends. Even those in employment are on very low incomes, some as little as US\$5.00 per week.

Although a remarkably cheerful group, keen to help each other, they were resentful of the apparent indifference of their Government and of the world to their plight. This may not be entirely justified, for the Rwandan Government's limited funds cannot meet identified needs. There is, however, little doubt of the world community's indifference.
One tragic indication of returning economic activity is the rising prevalence of road accidents. In the early days, the large lorries of the Aid Agencies and the extravagant provision of personal transport for the many officials of those agencies kept the limited road system busy enough. Now the huge commercial transcontinental lorries have added speed and congestion. Local machismo discourages the wearing of seatbelts, crash-helmets are virtually unknown and in the absence of public transport any open truck has all available space filled by standing passengers, with more clinging on top of the load.

In the absence of emergency services there is little help available, but survivors who reach one of the few hospitals, which have little modern equipment, often survive despite severe open or closed head injuries. Unfortunately, there is little recognition of the late, usually psychiatric consequences of head injury and even basic rehabilitation is lacking.

Sydney Brandon, 19 Holmfield Road, Leicester LE2 15D

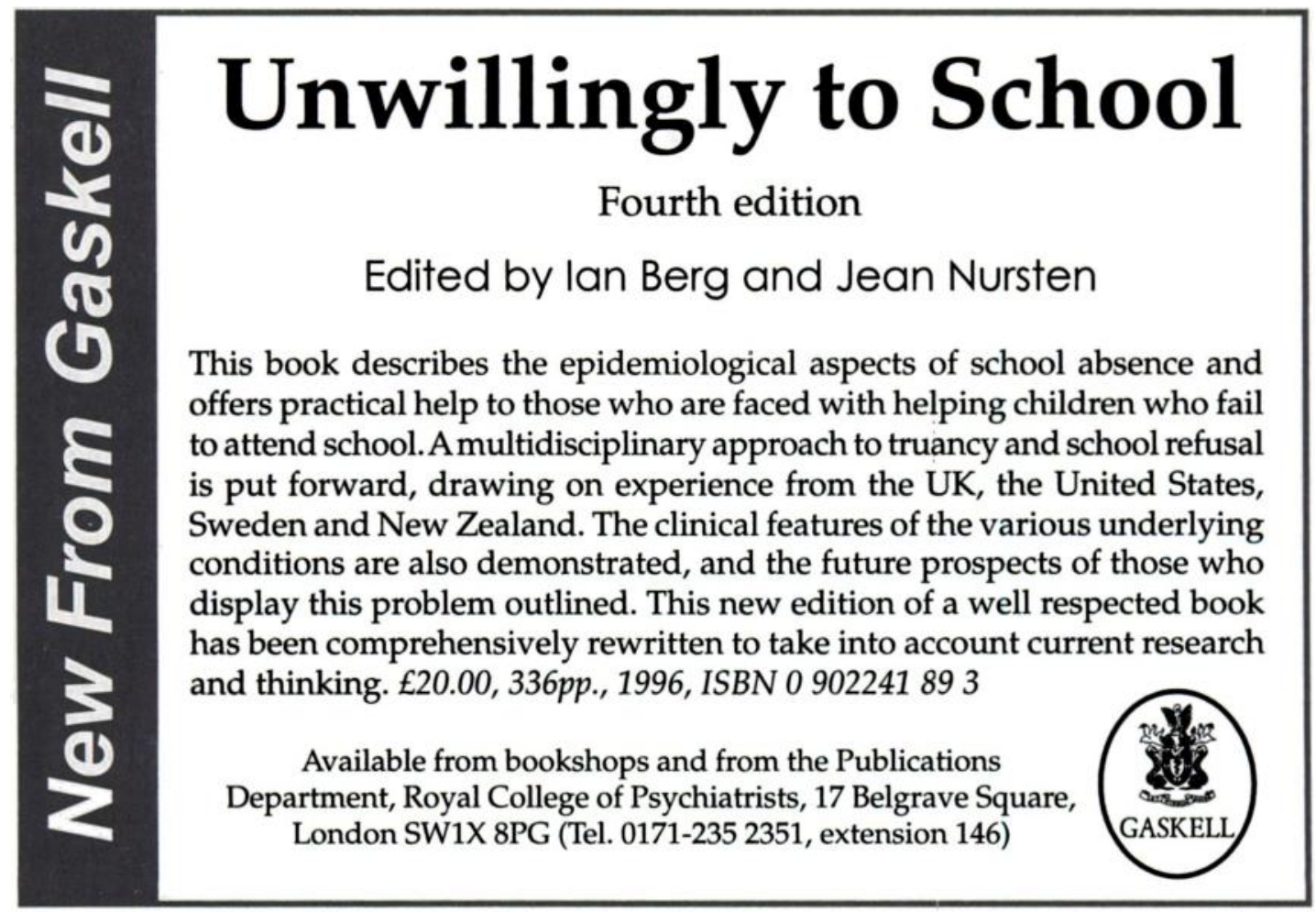

Note from Rwanda 